\title{
Sarcomas of the heart as a difficult interdisciplinary problem
}

Stanisław Ostrowski ${ }^{1,2}$, Anna Marcinkiewicz ${ }^{1,2}$, Anna Kośmider ${ }^{2}$, Ryszard Jaszewski ${ }^{1,2}$

${ }^{1}$ Department of Cardiac Surgery, Chair of Cardiology and Cardiac Surgery, Medical University of Lodz, Poland

${ }^{2}$ Military Teaching Hospital - Veterans Central Hospital, Lodz, Poland

Submitted: 28 October 2010

Accepted: 20 March 2011

Arch Med Sci 2014; 10, 1: 135-148

DOI: 10.5114/aoms.2014.40741

Copyright $\odot 2014$ Termedia \& Banach

\section{Abstract}

Cardiac tumors are assumed to be a rare entity. Metastases to the heart are more frequent than primary lesions. Sarcomas make up the majority of cardiac malignant neoplasms. Among them angiosarcoma is the most common and associated with the worst prognosis. Malignant fibrous histiocytoma comprises the minority of cardiac sarcomas and has uncertain etiology as well as pathogenesis. Transthoracic echocardiography remains the widely available screening examination for the initial diagnosis of a cardiac tumor. The clinical presentation is non-specific and the diagnosis is established usually at an advanced stage of the disease. Sarcomas spread preferentially through blood due to their immature vessels without endothelial lining. Surgery remains the method of choice for treatment. Radicalness of the excision is still the most valuable prognostic factor. Adjuvant therapy is unlikely to be effective. The management of cardiac sarcomas must be individualized due to their rarity and significant differences in the course of disease.

Key words: cardiac tumors, angiosarcoma, transthoracic echocardiography, surgery.

\section{Introduction}

The prevalence of primary cardiac tumors is estimated on $0.002-0.3 \%$ in autopsy series and $0.15 \%$ revealed on echocardiography [1]. In clinical practice, the diagnosis of heart tumor continues to pose difficulties. This state of affairs results in both their epidemiology and nonspecific clinical presentation. The diagnosis is delayed, which is especially significant in malignant tumors. Benign tumors after radical excision, even those of great size, have a good prognosis. Cardiac neoplasms long remain asymptomatic or mildly symptomatic. As often, symptoms are highly unspecific [2]. Clinical manifestation depends not only on the type of the tumor, but also on its size, location, mobility, and presence of a pedicle. This results in a varying degree of hemodynamic impairment and is followed by a diverse risk of complications, such as thromboembolism. Metastases to the heart occur more often than primary changes, from 20-40 up to 100 times more often, according to the source $[3,4]$. Only $25 \%$ of primary cardiac tumors are malignant, of which $95 \%$ are sarcomas and the remaining $5 \%$ include lymphomas [5]. The neoplastic process can spread multifocally or may create a single focus.
Corresponding author:

Assoc. Prof.

Stanisław Ostrowski MD, PhD

Department

of Cardiac Surgery

Chair of Cardiology

and Cardiac Surgery

Medical University of Lodz

Lodz, Poland

Phone/fax: +48 426331558

E-mail: stanislaw.ostrowski@

umed.lodz.pl 


\section{Primary cardiac sarcoma}

Primary cardiac tumors can be divided according to the location within the heart wall into epicardial, myocardial, endocardial and those with mixed location, involving more than one layer. Sarcomas are malignant tumors, derived from mesenchymal tissue. For these tumors the prognosis is unfavorable and the diagnosis is always given at a significantly advanced stage of the proliferative process. Different types of sarcomas are the most common primary cardiac tumors. They are a rare entity in children and infants [6]. These tumors tend to spread through blood, due to the specificity of immature blood vessels, extending in the neoplastic mass and devoid of endothelial lining. Cardiac sarcomas give metastases mainly to the lungs, but also to the lymph nodes, bones, liver and central nervous system (CNS) [6]. Although irradiation is one of the confirmed factors promoting their development, radiation-induced lesions are statistically rare and they concern mainly angiosarcoma, malignant fibrous histiocytoma (MFH), leiomyosarcoma, osteosarcoma, and lymphosarcoma [7]. Below we will try to cite the main characteristics of the most important cardiac sarcomas and provide a brief review of cases from the literature.

Angiosarcoma is by far the most common cardiac sarcoma, diagnosed in $25-40 \%$ of cases, mostly in men [8], and observed mostly in the third and fifth decade of life [9]. Ninety percent of them are situated in the right atrium $[8,9]$. Clinically it presents right ventricular heart failure. In the majority of cases the pericardium is involved and pericardial effusion observed, mostly hematic $[10,11]$. In the literature there are numerous reports of angiosarcoma clinical manifestations in the form of: pericarditis [9, 12, 13], valvular dysfunction [14, 15], coronary artery disease [13], tamponade [16-18], cardiomyopathy, and even heart rupture (7 cases) [19]. Angiosarcoma can imitate pulmonary embolism [15] or a myxoma [20] and even grow within the interventricular septum [21]. That does not affect the therapeutic course, which is surgical anyway. However, it significantly changes the prognosis and postoperative treatment and should lead to more accurate diagnosis of such patients. The suspicion of a sarcoma should undoubtedly speed up the operation. As a low differentiated neoplasm with high malignancy, angiosarcoma can have an urgent course with rapidly increasing pericardial effusion, requiring even drainage [22] and a drastically increasing tumor mass with metastasis to the lungs, liver and to the brain [23]. A Liombart-Cussac et al. noted that in angiosarcomas median time to progression is shorter (average 4 months) than in other types of sarcomas (13 months) [24]. Survival after establishing the diagnosis does not exceed 1 year [4]. Refraining from the surgical procedure and initiating only conservative therapy, chemotherapy or radiotherapy, ensures only 9 to 12 months survival [23]. Histologically, angiosarcoma is composed of atypical endothelial cells, forming numerous irregular vascular spaces, which in fact can be visualized during cardiac ultrasound with color Doppler. Morphologically the tumor appears mostly as a heterogeneous mass with hemorrhagic and necrotic foci, widely invading the surrounding tissues.

Rhabdomyosarcoma (RMS) is derived from the myocardium. It is considered to be the most frequent primary cardiac tumor in children and the second most common in adults $[25,26]$. It makes up $20 \%$ of primary malignant cardiac tumors. In some publications the authors suggest low differentiated sarcomas as the commonest and mention angiosarcoma and leiomyosarcoma in the second place [4]. High malignancy and especially delayed clinical manifestation result in 6-month survival after the diagnosis [27]. The first symptoms are associated with occupying cardiac cavities and invading the pericardium. At this point metastases are usually already present and they affect the lungs, local lymph nodes, mediastinum and the bones of the spine [28]. Although this sarcoma is not restricted to any cardiac cavity [8], some authors claim that it involves more often the ventricular muscle. Myocardial tumors occur typically within the free wall of the left ventricle or the interventricular septum [29]. Only occasionally they are located in the atria, resulting in stenosis [30]. Analogically to angiosarcoma, they are nearly one and a half times more often observed in men. There are two forms of rhabdomyosarcoma: embryonal and pleomorphic adult type. Sometimes the alveolar type is mentioned as the third. Multifocality and predilection to valvular structures are specific features of this sarcoma. There are publications about the role of immunohistochemical reactions with Carp protein and its homolog Arpp in the diagnostic process and rhabdomyosarcoma's differentiation. In RMS cells high expression of both was noted, which allows it to be clearly distinguished from other sarcomas [31]. The case of a 51-year-old man misdiagnosed as a fibromyxoma, with extensive infiltration of nearby structures and numerous metastases to the lungs in the $3^{\text {rd }}$ month after surgery, demonstrates the role of immunochemistry in the histopathological examination [28]. In the literature there was described synchronous co-existence of hypereosinophilia and rhabdomyosarcoma. It is related to spread of the disease and worse prognosis. Production of cytokines by the tumor cells and their myeloproliferative action seem to be the main cause $[32,33]$. Additionally, in the course of hyper- 
eosinophilic syndrome (HES) secondary myocardial lesions develop and can occur as heart failure, valvular dysfunction, endocarditis or restrictive cardiomyopathy [34]. It evokes the image of a vicious circle. These patients are at increased risk of thromboembolic events. Curiously, one of the basic medications in hypereosinophilic syndrome is the tyrosine kinase inhibitor imatinib, widely used in sarcoma treatment. The molecular basis of HES is connected with translocation within the genes of the protein group PDGFR, which are located in chromosomes 4, 7, 11, 22. So far only a link between leiomyosarcoma and $5 q$ and $13 q$ pathology has been proved. Studies revealed $19 q$ aberration for progressing MFH. The participation of changes in GTP-ases such as HRAS (chromosome 11), KRAS (chromosome 12) and RB1 (chromosome 13) in sarcoma pathology was found [35]. Currently, the molecular diagnosis of a sarcoma is possible in approximately $50 \%$ of cases.

Leiomyosarcoma is a sarcoma of smooth muscle fibers, which in terms of location can be divided into deep soft tissue sarcomas, skin and subcutaneous tissue sarcomas, those originating from the vascular system and bone sarcomas often singled out separately due to their extremely rare occurrence. Those with vascular etiology are generally situated in the venous system and only exceptionally concern great vessels. If so, the vena cava inferior is involved most frequently. In the arterial system it invades the pulmonary arteries. This difference in predilection to particular vessels is connected with the anatomical structure of its wall and resistance to high pressure. Large veins are composed of a greater amount of smooth muscles. In the arterial system high pressure results in the dedifferentiation to cells producing fibrous elements such as collagen and elastin [36]. The above states permit the initiation of the neoplastic process. So far, only 400 cases of great vessel leiomyosarcomas have been reported. They concerned the vena cava inferior, pulmonary arteries and the thoracic aorta [36]. They originate from the multipotential mesenchymal cells of the internal vascular wall. Localization of the tumor in the great vessels promotes a direct way of spreading to the heart. In contrast, when situated initially in the cardiac cavities, they cause oppression or impedance of blood flow in these vessels. According to Vaello et al. the vena cava superior syndrome may be the first sign of the presence of an intracardiac mass [37]. Frequently, it is problematic to determine the initial tumor etiology - cardiac or vascular - especially as pulmonary vein infiltration is part of atrial leiomyosarcoma characteristics. Cardiac leiomyosarcoma can begin in the vascular system supplying the heart muscle or in the endothelium lining the cardiac atria or originating from smooth muscles, which normally create bundles in the subendocardial layer of the left atrial wall. It makes clear its preferential location inside the heart. A specific group of leiomyosarcoma, typical for immunocompetent patients, is also known. Leiomyosarcomas represent only $5-10 \%$ of all types of sarcomas [38]. They are found more often in women [39]. In the heart they are rare, with prevalence of $8-9 \%$ and less than $0.25 \%$ of all primary cardiac tumors. Hattori mentions only 38 cases of primary cardiac leiomyosarcomas [39]. In half of cases they are situated in the left atrium [36], resulting in frequent diagnostic confusion with the most common primary cardiac tumor, myxoma. Additionally, the differentiation is complicated by a myxomatous echocardiographic image. The presence of a pedicle and connection with the interatrial septum, typical for myxomas, as the lack of mobility indicating the malignancy, are insufficient criteria [40, 41]. However, intraoperative evaluation of the structure according to its coherence, tendency to defragmentation or infiltration of the base should raise some suspicions and lead to intraoperative frozen examination. Pericardial effusion as a sign of malignancy can be absent due to adhesion of the plaques [36].

Histopathological differentiation may not give a clear answer and may even be faulty due to the microscopic image resembling a myxoma. The presence of abundant, myxomatous stroma may suggest a myxoma. With tumor progression, the histopathological picture with enlarging cellularity, mitotic activity and fields of dedifferentiation to osteo- or chondrosarcoma begins to be pathognomonic for malignancy [36, 42]. The diagnosis is confirmed by positive immunohistochemical reactions with SMA, desmin and vimentin, and, if there are other doubts, electron microscopy. Immunochemistry is decisive also in the troublesome differentiation with fibromyxosarcoma. "Lepidic cells", low differentiated, multipotential, mesenchymal cells, which tend to form primitive vessels, are also typical for myxoma [42]. The external stratum, enclosing the abundant myxomatous ground, is also a characteristic part of the microscopic presentation. The median survival for leiomyosarcoma after surgical intervention with continuation of radio- or chemotherapy is estimated at approximately 7 months [43]. Vessel invasion and necrosis are among the especially useful prognostic criteria [44] (Figure 1).

Fibrosarcoma and fibroblastic sarcoma are the names used in the literature for a sarcoma derived from fibroblasts. There is also known a subtype myxoid fibrosarcoma, fibromyxosarcoma or myxofibrosarcoma - comprising $10 \%$ of all fibrosarcomas [45]. Fibrosarcoma is diagnosed in $11 \%$ of cases of cardiac malignant tumors [46]. According 
to the pathomorphological classification there can be listed a few types of fibrosarcomas with different levels of malignancy (WHO's STS classification from 2002):

- Myxoinflammatory fibroblastic sarcoma,

- Infantile fibrosarcoma, both mild malignant, rarely metastasizing.

However, as malignant tumors there are classified:

- Adult fibrosarcoma,

- Myxofibrosarcoma, known in the past as a myxoid type of MFH,

- Low-grade fibromyxoid sarcoma and hyalinizing spindle cell tumor, which are closely related tumors with the same molecular pathomechanism (gene fusion FUS/CREB3L2), differentiating only in the morphological picture - the presence of collagenous rosettes in hyalinizing tumor,

- Sclerosing epithelioid fibrosarcoma - histopathologically a benign tumor, clinically with high potential for infiltration and metastasis [47].

The last three types are grouped as fibrosing fibrosarcomas.

The tumor's histopathological appearance depends on the grade: low with well-differentiated cells or mild and high with bad resemblance to the parent tissue. Microscopically, there are displayed immature fibroblasts and atypical spindle cells, a variable amount of collagenous fibers, and variable mitotic activity (Figure 2).

As lower differentiated sarcoma, and thus pleomorphism, mitotic and cell atypia, including multinuclearity, presence of huge cells or fields of necrosis and stroma reduction instead of high cellularity are more emphasized. The most characteristic histopathological feature is 'herringbone' or 'resembling fish bone' composition of its structures. The clinical presentation of this sarcoma is the same as in other cardiac tumors. Lim et al. pre-

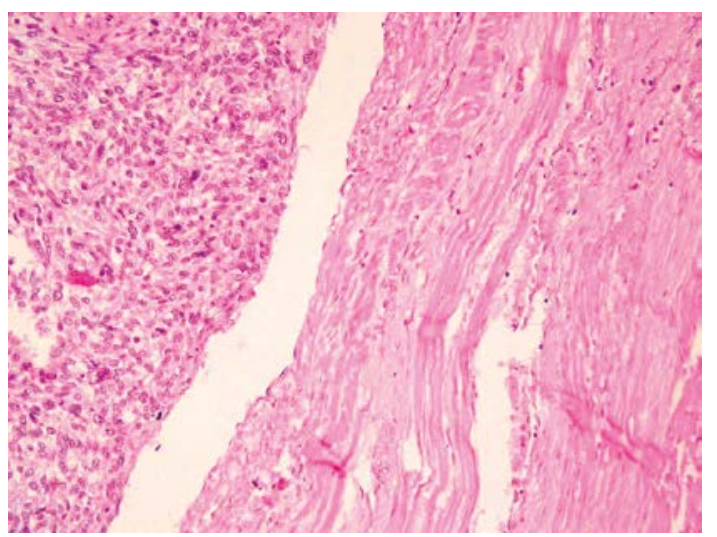

Figure 1. Leiomyosarcoma - microscopic image presenting abundant, myxomatous stroma with high level of cellularity and fields of dedifferentiation. Pathomorphology Department, Medical University in Lodz sented the case of a 43-year-old man with a huge tumor, enclosing almost the entire heart and large vessels. The patient was admitted to the clinic with acute heart failure. It not only shows the invasiveness but also proves the asymptomatic nature of the cardiac tumor at the early stages of development [48]. This case is also an example of pericardial location of a primary cardiac tumor. However, that kind of localization is a typical feature of metastases [21]. It is worth mentioning that fibrosarcoma as a sarcoma originating from the fibrous tissue provides an excellent base for the creation of a thrombus, which can overrate the actual mass of the tumor. Fibrosarcoma and the above-described leiomyosarcoma are most commonly observed for gradual histopathological progression in subsequent recurrences and are based on slow loss of the neoplastic tissue differentiation [49]. Fibrosarcoma is more often a component of other sarcomas, accounting for only $1-3 \%$ of all adult sarcomas $[50,51]$. Most frequently it gives metastases to the bones, mainly the spine, and to the lungs [50]. It has a tendency to nodular growth. It may appear as a result of radiation or occur in the vicinity of a foreign body. In the literature there is a description of a malignant transformation of an inflammatory myofibroblastic tumor (IMT) called an inflammatory pseudotumour into an inflammatory fibrosarcoma, which grew around an implanted dual chamber pacemaker [52]. The lowgrade myxomatous fibrosarcoma subtype tends to give recurrences as well as local metastases. It requires an extensive excision with a wide healthy tissue margin. High-grade sarcomas give metastases generally to the lymph nodes, lungs, bones or the brain [53]. Fibrosarcomas rarely involve the lymph nodes. Myxofibrosarcoma was suggested to be a variety of MFH. Ultrastructural examination confirmed its fibroblastic etiology. In the liter-

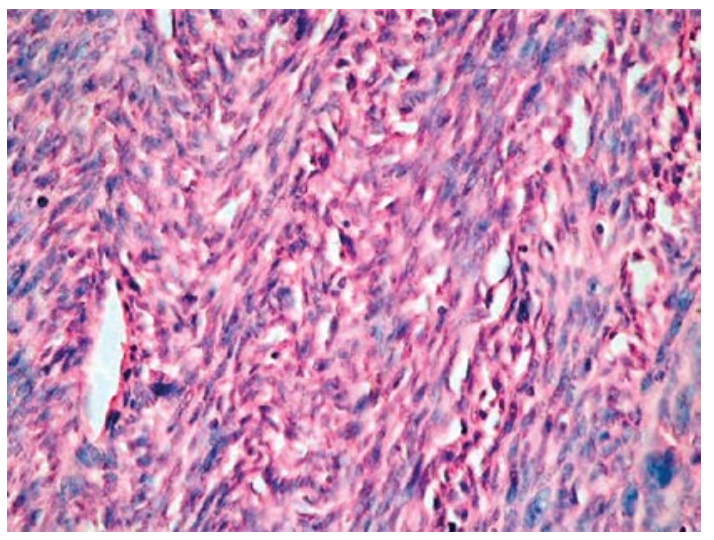

Figure 2. Fibrosarcoma - immature fibroblasts and atypical spindle cells, a variable amount of collagenous fibers, and variable mitotic activity. Pathomorphology Department, Medical University in Lodz 
ature there are only 7 cardiac myxofibrosarcoma cases reported, including 4 in the left atrium [53].

Osteosarcoma and above-mentioned fibrosarcoma are the rarest of cardiac sarcomas. There have been only a few cases of primary cardiac osteosarcomas recorded [54]. Additionally, it is the most common bone malignant tumor. Extraosseous localization and occurrence in the elderly are more typical for its variants than for the classical type. Osteosarcoma is classified as an osteoblastic, chondroblastic or fibroblastic variant, as well as the MFH-like, telangiectatic, epithelioid, giant-cell rich, high-grade central type [55]. Primary cardiac osteosarcomas make up only 3-9\% of all heart sarcomas [56]. By 2007 there were only 37 cases of them described in the literature [46]. The majority of cases clinically were connected with acute heart failure, preceded by a few months case history of nonspecific symptoms such as dyspnea, weakness, and poor exertion tolerance. This sarcoma type occurs preferentially in the left atrium [57] and is frequently mistaken for myxoma. The secondary lesions affect mainly the right heart [58]. Cardiac osteosarcoma metastasizes infrequently to the regional lymph nodes. In 1984 Schneiderman et al. reported a 77-year-old male with an osteosarcoma extending over the right and anterior part of the heart, apex and the great vessels. The tumor's removal appeared to be impossible due to the extent of the neoplastic invasion and significant tissue calcification, which led to constrictio cordis. Most of the right ventricle myocardium was damaged by the neoplastic process. The autopsy revealed extensive coronary microvascular invasion and metastases in the lymph nodes [59]. It is another example of extracardiac localization of a primary lesion. The presence of calcified tissue creates a characteristic image of hyperechogenic areas, visualized by both computed tomography (CT) and echocardiography. Bone scintigraphy is used in order to determine the primary focus or monitor disease progression. The pathomorphological image displays atypical cells with numerous abnormal mitoses. The stroma is rich in countless irregularly arranged osteoid islets with variable calcification and containing clusters of anaplastic sarcoma cells. Islets of cartilaginous tissue can be seen. Characteristic blood vessels without endothelial layer are also common.

Malignant fibrous histiocytoma is an acronym identifying malignant fibrohistiocytoma. Although it appears officially in the WHO's classification as originating from fibrous tissue, MFH is assumed to be a pleomorphic, high-grade sarcoma with still unknown etiology and pathogenesis. It is the most common sarcoma of adults, but the rarest cardiac sarcoma. Initially, the names pleomorphic fibrosarcoma and myofibrosarcoma were used for it.
In 1967 the current name was officially approved, before "facultative fibroblasts" had been wrongly claimed to originate from histiocytes $[50,60]$. Since then there have been reported many more MFH cases, although many of them were just misdiagnosed pleomorphic sarcomas of other lines. This continued until the ultrastructural and immunohistochemical examination allowed the accuracy of these assessments to be verified. More recent studies applying hybridization have included the presence of multiple genetic aberrations in $\mathrm{MFH}$, which are specific to dedifferentiated liposarcomas or leiomyosarcomas, suggesting unreliability of MFH as a distinct clinical entity [61]. This led to a theory that MFH is a common pattern of histopathological progression for many lines of poorly differentiated sarcomas [62]. Fletcher et al. selected the primary cellular line, typical for other sarcomas in $84 \%$ of 100 cases originally diagnosed as MFH [63]. However, they highlighted the clinical significance of MFH. Pleomorphic sarcomas with signs of myogenic differentiation were connected with worse prognosis. Those cases had shorter survival due to greater tendency to metastasis and local recurrence [63]. Currently, the frequency of malignant fibrohistiocytoma is evaluated at $5 \%$ [62]. Confusion about issues of the pathogenesis and etiology as well as MFH diagnostics explains the particular contradictory findings. The pathomorphological picture of MFH abounds in myxomatous fields, which can result in misdiagnosing myxoma instead [64]. Especially, MFH also occurs preferentially in the left atrium [65].

The WHO's classification maintains the false histiocytic origin:

- Pleomorphic MFH,

- Gigantocellular MFH,

- Inflammatory MFH.

The former angiogenic subtype was included in tumors of uncertain differentiation.

Most of the extensive analyses of fibrohistiocytoma prognostic factors are based on extracardiac tumors. Ahlén et al. [66] examined the immunohistochemical parameters in 65 primary MFH of low diversity. A significant correlation between tumor diameter of more than $8 \mathrm{~cm}$ and high expression of $\mathrm{Bcl}-2$ protein with formation of metastasis and recurrence was established. The mitotic activity affected the length of remission. However, the distinction between $3^{\text {rd }}$ and $4^{\text {th }}$ degree of malignancy was proved to be clinically insignificant. Surprisingly, the presence of necrosis within the tumor did not influence the clinical effects. Gibbs et al. [67] confirmed the predictive value of grading, tumor size and the presence of metastases at the moment of diagnosis. Ten-year survival was recorded for $90 \%$ of patients with low grade sarcomas, $60 \%$ with intermediate and $20 \%$ with 
high grade. If the size of the tumor was $<5 \mathrm{~cm}$ the overall survival was approximately 4 times higher than for patients with tumor $\geq 5 \mathrm{~cm}$. Initially, there were distant metastases diagnosed only in $5 \%$ of patients. None of these patients lived longer than 90 months. Molecular analysis helped to determine the presence of aberrations within the $19 q 13$ locus, which promoted the creation of more frequent recurrences and metastases in patients with MFH [68]. Unlike most cancers, neoplastic angiogenesis does not play a role in metastasis of fibrohistiocytoma [69]. The presence of a ring and dicentric chromosome is relatively frequently observed. Progression of chromosome lesions is characteristic for local recurrence [65]. Fibrohistiocytoma often presents the paraneoplastic inflammatory syndrome, which is a bad prognostic sign [70]. For soft tissue sarcomas a positive correlation between serum concentration of IL- 6 and IL-8 and the level of histological tumor malignancy was found. Simultaneously, decreased overall survival was observed [71]. Recchia et al. [72] reported a case of metastatic cardiac MFH treated with aggressive chemotherapy, followed by autologous peripheral blood cell transplantation and immunotherapy. Immunotherapy with IL-2 and 13-cis retinoic acid (RA) was initiated in stable disease and continued for 3 years. Complete response in magnetic resonance imaging (MRI) was achieved. The patient was asymptomatic. Eventually he died of ventricular arrhythmia. A histological diagnosis of MFH is placed on the exclusion of other pleomorphic, poorly differentiated sarcoma lines and cancers or melanoma metastases. The results of immunohistochemical studies have fundamental importance. Malignant fibrous histiocytoma usually shows a positive reaction to vimentin, but other markers are mostly negative [62]. Ultrastructural analysis can provide conclusive data. Fibrohistiocytoma is resistant to both conventional radio- and chemotherapy [73]. In turn, the experience of other centers confirmed the beneficial effect of radiotherapy in reducing the risk of local recurrence [74]. Ten-year observation of the Rizzoli Orthopedic Institute also showed the satisfactory effect of neoadjuvant chemotherapy [75]. These data are based on extracardiac tumors. Malignant fibrous histiocytoma case studies should be considered with appropriate caution because of the alterations in the nosology of this sarcoma. However, we cannot quite agree with some authors [62] that this is the cause of such varied patient responses to therapy and the tendency to recurrence and metastases. The fact is that most pleomorphic sarcomas regardless of histological type of differentiation (excluding the general division of myogenic and non-myogenic) have a poor response to adjuvant therapy. The overall survival is not significantly improved, in spite of good response observed in examinations. Rather, molecular alterations in individual cases of MFH seem to be responsible. By 2002, there were only 42 cases of patients with primary cardiac MFH, of whom the youngest patient was 16 years old [76].

\section{Secondary cardiac sarcomas}

Metastases to the heart can be formed either directly by infiltration from the surrounding structures or indirectly through the blood and lymph. Depending on that, they occupy intracardiac cavities or are localized on the cardiac external faces, causing heart failure or low output syndrome. Pericardium is most commonly involved within the course of metastases to the heart [77]. Secondary lesions, like primary ones, may invade each of the cardiac wall layers and give a similar clinical presentation, in particular, pericardial effusion as a result of coronary microvasculature damage due to direct infiltration, secondary released proinflammatory or damaging substances and neoplastic microembolism [55]. Neoplastic spread within the myocardium or epicardium occurs almost exclusively backwards by the lymphatic system, after earlier invasion of the pericardium [55]. Metastases via blood circulation first affect the endocardium. Secondary lesions in the heart usually appear in an advanced stage of an extracardiac primary tumor [78]. Maheshwari et al. presented the case of a 29-year-old man with an isolated metastasis to the heart of an undifferentiated sarcoma of the lower limb [79]. According to an autopsy series, there is significant incidence of secondary cardiac tumors in the absence of a clinical manifestation [77]. Certainly, their asymptomatic nature depends partially on their pericardial location. Their prevalence is estimated at $2.3 \%$ to $18.3 \%$ [55], and even $25 \%$ according to some authors [80]. In the Hallahan study almost half of the 120 patients with soft tissue sarcomas presented cardiac metastases [81]. Diagnosis is further complicated by the primary malignant process, masking the symptoms from the circulatory system, non-specific anyway. The usual right-side localization of sarcoma metastases [82] is a result of the lower pressure, less systolic strength and slower blood flow through the right heart [55]. Spreading through blood, metastases preferentially invade the endocardium, from where they can infiltrate the myocardium and grow exophytically into the heart chambers, usually without reaching significant proportions. Coller et al. reported the case of a large fibrosarcoma metastasis, impeding the left ventricular outflow. It occurred 9 years after surgical excision of the primary lesion in the left wrist [77]. The ability to give rise to metastases even after such a long asymptomatic period is 
a typical feature of sarcomas. It should be recalled that the term metastasis to the heart includes the neoplastic involvement of large vessels, entering or leaving the heart, and an intracardiac thrombus, formed by an extracardiac neoplastic process, and being part of the paraneoplastic syndrome [55]. At the time of the disease dissemination a serious problem of tumor embolism is likely to develop. It not only leads to peripheral vascular obstruction, but also alters pressure and hemodynamic relationships, resulting in the change of the lymph flow direction within the complex intracardiac lymphatic system and affecting the intracardiac spread of micrometastases [55]. In the literature there are descriptions of heart involvement through direct intravascular infiltration from an extracardiac sarcoma. Kelle et al. reported the case of a 72-year-old female with a fibrosarcoma of the liver right lobe, which extensively infiltrated the inferior vena cava and then spread to the right atrium and tricuspid valve [83]. Another example is the case of a 23-year-old woman with an osteosarcoma, which arose through the left femoral vein via the external iliac vein, common iliac vein, the vena cava inferior and reached the right atrium stretching up to the right ventricle. The primary origin was located in the sacrum, from where it spread to the spine and pelvis [55]. Metastases to the heart are now more frequently recognized, and this is due to improved diagnostic methods and prolonged survival of patients with malignancies. On the other hand, many of them remain undetected because of restrictions on carried out post-mortem examinations.

\section{Imaging methods}

Transthoracic echocardiography is a widely available screening examination and remains the basic test for cardiac tumors. Extended analysis requires transesophageal echocardiography, particularly useful for visualization of changes within the left atrium, small tumor or infiltration beyond the pericardium [6]. Magnetic resonance imaging is also used in the diagnosis and assessment of cancer foci or metastases, establishing the tumor's malignancy and distinguishing the tumor from a thrombus. It gives far greater opportunities, incomparably better visualization of pathological structures and is more sensitive than echocardiography [1]. The only limitation seems to be the cost and availability. The role of $\mathrm{CT}$ in obtaining complete characterization of the cardiac tumor is also indisputable. The greater part of this study is to illustrate the accompanying changes in the large vessels, pericardium, pericardial sac or distant lesions and alterations in the nodes. Some authors suggest the superiority of $M R$ and $C T$ imaging methods in the preoperative tumor as- sessment to the generally used echocardiography, which should be applied in the initial diagnosis and patient monitoring. Exarhos et al. delineated and diagnosed correctly $100 \%$ of cardiac masses, using CT, MR and PET-CT [84].

\section{Diagnosis}

A non-specific, and even misleading clinical picture significantly impedes the diagnosis of cardiac sarcoma. As it turns out, even direct biopsies of tumors within the heart and histopathological examination of a taken tissue fragment may be insufficient to establish the correct diagnosis. Japanese researchers described the case of a 50-year-old male patient who was originally diagnosed in this way as an organized thrombus in the right atrium. Metastases to the vicinity of the third rib and the biopsy revealed angiosarcoma [85]. Interestingly, the diagnosis of this tumor is most frequently given on the basis of histopathological assessment of a tissue fragment from the metastasis.

\section{Treatment}

Cardiac tumors, whether primary or metastatic, are treated surgically. Open-heart surgery through the median sternotomy access is performed with cardiopulmonary bypass and involves excision of the change together with a fragment of the wall from which the tumor originated. The stage of tumor growth frequently makes radical excision impossible. These are often operations significantly damaging the myocardium. Reconstruction of the heart wall using porcine pericardium or synthetic Dacron patches is needed. The problem to remove sarcoma infiltrating the myocardium is connected with the absence of appropriate material that can be employed to supplement the loss [86]. In the case of anatomic barriers in the resection of the tumor mass, operations of ex vivo removal and autologous transplantation of the heart are conducted. In the authors' opinion, the therapeutic outcome for sarcomas depends on the RO resection. So in reasonable cases the mentioned method should be applied. Even the right heart can be resected almost completely and reconstructed using Fontan circulation [87]. In the literature, there is also a case of total resection of the left atrium and its orthotopic allograft transplantation due to leiomyosarcoma [88]. On the other hand, the analysis undertaken by Vitovskil showed that breadth of the operation has no significant effect on the clinical status of patients in the immediate period after surgery [89]. In fact, it is difficult to make an objective assessment of the resection as a prognostic factor, since the majority of sarcomas are diagnosed at a significantly advanced 
stage, often with distant metastases. When the valvular structure is altered by the neoplastic process, usually implantation of a prosthetic valve or bioprosthesis is required. Currently, many centers employ the endoscopic method to remove tumors from the left atrium, obtaining good results. These operations are usually not preceded by a biopsy of the tumor and histological assessment of its malignancy. In most cases, postoperatively a myxoma is confirmed [90]. This method was also applied to a left ventricular fibroelastoma [91] and for a synovial sarcoma of the left atrium with intraoperative microscopic tumor assessment, including radicalness of the resection [92]. The incidence of recurrences after removing the tumor is relevant. However, radical surgery is the primary prognostic factor [93]. In some publications, there is emphasis on the problem of local recurrence after tumor excision, in spite of carrying out radical surgery $[24,94]$.

Matsumoto et al. [94] estimated it even at $12.3 \%$ of cases. On the other hand, many researchers emphasize the superiority of combination therapy, which helps one to achieve up to twice as long survival (median survival was 24 months compared to 10 months). But it could be achieved only in patients with primary radical resection [95]. Shanmugam drew attention to an important aspect of supplying the bleeding during cardiac sarcoma resection and subsequent recovery of blood from the heart-lung device, which entails the possibility of spreading the tumor [96]. In the further course of treatment the patient is subjected to adjuvant treatment, chemo- and/or radiotherapy, depending on the diagnosis established by histopathology, and clinical status. Documentary data show good local management of recurrences or residual disease obtained with the assistance of radiotherapy in many cases. The main restriction is the cardiotoxic dose (about 6500 cGy) which should be applied for curative purpose. Hyperfractionated radiotherapy and use of radiosensitizers may avoid side effects (a dose of 4000 cGy results in pericarditis in $40 \%$ of patients) [97]. There were four regimens for soft tissue sarcoma treatment: CAD (cyclophosphamide, Adriamycin/doxorubicin, dacarbazine), AD (Adriamycin), CYVADIC (cyclophosphamide, vincristine, doxorubicin, dacarbazine), and VAC (vincristine, doxorubicin, cyclophosphamide). Some remain as those of significant clinical input. Others, like CYVADIC, can be applied in a clinical situation when a standard regimen cannot be used. According to current data, anthracycline based chemotherapy (Adriamycin/doxorubicin + ifosfamide) is recommended [98]. In the case of anthracycline resistance, sorafenib or trabectedin can be used in soft tissue sarcomas (STS). However, sorafenib gives only a 6-month progression-free rate of about $20 \%$ of patients with angiosarcoma [99]. The second regimen is gemcitabine with docetaxel (or paclitaxel). In the literature there is a case of an angiosarcoma treated with docetaxel and radiotherapy reported. The patient was disease-free after a year of follow-up [100]. Bakaeen et al. [101] proved the role of multimodal treatment. In their study 12 patients out of 27 were alive (median follow-up 22 months) after surgery accompanied by pre- or postoperative chemotherapy. Postsurgical continuation of treatment for recurrences with radiotherapy allowed median survival of 47 months to be achieved (but only in 7 patients). Sala et al. [102] investigated participation of neoadjuvant therapy in locally advanced STS. The authors achieved overall survival of 83.6 months and disease-free survival of 78.29 months. Angiosarcoma reacts badly to the chemicals, while the results of treatment of rhabdomyosarcoma in children are satisfactory. Response to chemotherapy or radiotherapy of all advanced sarcomas is unfavorable. The median survival ranges from 7 to 12 months. The increase in overall survival is not significantly high [103]. Oechsle et al. [104] observed some response (partial in 1 patient and stable disease in 3) after applying palliative chemotherapy in $7 \mathrm{pa}-$ tients with cardiac sarcomas. Mayer et al. [105] reported median survival of 17 months in patients with heart and great vessel sarcomas. Treatment involved, besides surgery, adjuvant/neoadjuvant, palliative chemotherapy and irradiation of brain metastases and primary lesion (1 case). Curiously, the authors achieved one complete remission after palliative chemotherapy lasting $>10$ years. An additional limitation in the use of adjuvant therapy is the potential cardiotoxicity. This applies to both radiotherapy and chemotherapy, based primarily on anthracyclines [106]. The modern approach to treatment of a sarcoma is focused on the use of molecular pathomechanisms of their development and application of the targeted therapy. It involves anti-angiogenic drugs, which can inhibit the variable quantity of angiogenic proteins (bevacizumab targets VEGF and sunitinib or sorafenib are multi-targeted tyrosine kinase inhibitors) [98]. In the case of tumors with vascular etiology such as angiosarcoma, the potential benefits of treatment with anti-angiogenic substances - bevacizumab, sunitinib, sorafenib - seem to be most obvious. The current study revealed an in vivo decrease in the microvessel density and tumor volume (reduction to 48\%) in MFH [107]. There are studies of the use of mTOR or IGFR1R inhibitors in rhabdomyosarcoma treatment [108]. However, mTOR inhibitors also cause an anti-angiogenic effect due to lowering the VEGF level. As a result they can provide benefits in patients with angiosarcoma. 
To our knowledge, there is no study evaluating the role of mTOR inhibitors in cardiac sarcomas. However, there was a study designed to assess ridaforolimus in patients with sarcomas, all types. The second phase, completed recently, revealed an overall clinical benefit response rate of $29 \%$. The overall survival (OS) of these patients was 67.6 weeks in comparison to the median OS of 40.1 weeks for the entire study population [109]. In the literature there are mentioned attempts of imatinib usage in adjuvant therapy, although it is not officially registered as a drug for cardiac sarcoma therapy. In the presented case, despite the use of imatinib, recurrence appeared within 5 weeks [53]. The main limitation is, however, the potential cardiotoxicity of imatinib or bevacizumab [110]. Recent studies draw attention to the simultaneous effects of targeted therapy for cardiac transmission mechanisms and the consequent impairment of growth and apoptosis of these cells [111]. It should be said that anti-angiogenic therapy is preferred in slow-growing tumors and anti-mitotic in rapidly-growing ones, although there is a tendency to combine cytotoxic chemotherapy with targeted therapy, especially in rapidly-growing, endothelial derived angiosarcomas [98]. Tumors not qualified for resection may also be an indication for heart transplantation, although survival of these patients does not favor such a solution [86, 112] (Table I). It is suggested that there is a relationship between relapse after transplantation with the applied immunosuppression. However, there was described a case of long-term survival after orthotopic heart transplantation because of the original rhabdomyosarcoma [113].

\section{Summary}

The first 2 years after surgery and adjuvant treatment are the decisive period for the patient with a diagnosis of soft tissue sarcoma [114]. Eighty percent of lung metastases and $70 \%$ of local recurrences are recorded at that time. Five-year survival ranges widely from $35 \%$ to $75 \%$, and the histological grade of malignancy and tumor size are of the most important prognostic significance [115]. The classification of the American Joint Committee on Cancer (AJCC) is commonly used in order to assess the sarcoma's clinical stage.

So far no grading scale for cardiac sarcomas or TNM system adapted to the needs of cardiac surgery has been created [116]. Cardiac sarcomas continue to have an unfavorable prognosis [117]. Among publications, there is little literature identifying prognostic factors for cardiac sarcomas. According to all independent researchers, radical excision determines the formation of local tumor

Table I. Clinical staging according to AJCC/UICC (1997)

\begin{tabular}{|c|c|c|c|c|}
\hline \multicolumn{5}{|l|}{ Prognostic categories } \\
\hline T - tumor size & \multicolumn{4}{|c|}{ Location of the tumor } \\
\hline $\mathrm{T} 1 \leq 5 \mathrm{~cm}, \mathrm{~T} 2>5 \mathrm{~cm}$ & \multicolumn{4}{|c|}{ A - superficial, B - deep } \\
\hline $\mathrm{N}$ - local lymph nodes & \multicolumn{4}{|c|}{ NO - lack of metastases, N1 - metastases present } \\
\hline M - metastases to distant organs & \multicolumn{4}{|c|}{ MO - lack of metastases, M1 - metastases present } \\
\hline G - histological grade & \multicolumn{4}{|c|}{ G1-2 low, G3-4 high } \\
\hline \multicolumn{5}{|l|}{ The advanced stages } \\
\hline Stage & G & T & $\mathrm{N}$ & M \\
\hline I & G1-2 & T1A-1B, 2A & NO & MO \\
\hline \multirow[t]{2}{*}{ II } & G1-2 & $\mathrm{T} 2 \mathrm{~B}$ & NO & MO \\
\hline & G3-4 & T1A-1B, 2A & No & MO \\
\hline III & G3-4 & $\mathrm{T} 2 \mathrm{~B}$ & NO & MO \\
\hline \multirow[t]{2}{*}{ IV } & G1-4 & Each T & N1 & MO \\
\hline & G1-4 & Each T & Each N & M1 \\
\hline \multicolumn{5}{|l|}{ Discussion } \\
\hline \multicolumn{5}{|c|}{ I - Low malignancy, MTM $<5 \mathrm{~cm}$ (superficial and deep) and $>5 \mathrm{~cm}$ (superficial) } \\
\hline \multicolumn{5}{|c|}{$\begin{array}{l}\text { II - Low malignancy, MTM }>5 \mathrm{~cm} \text { (deep) or } \\
\text { - high malignancy, MTM }<5 \mathrm{~cm} \text { (superficial and deep) and MTM }>5 \mathrm{~cm} \text { (superficial) }\end{array}$} \\
\hline \multicolumn{5}{|c|}{ III - High malignancy, MTM > 5 cm (deep) } \\
\hline IV - Metastases (N1 or M1) & & & & \\
\hline
\end{tabular}


recurrence and survival $[55,67,94,116,118]$. Gustafson's analysis also shows that the share of prognostic factors varies for each line of sarcomas [44]. Truong et al. reported that for the cardiac sarcomas only the presence of metastases at diagnosis and radical treatment are significant. Chemotherapy and radiotherapy, or other parameters such as age, sex, the degree of malignancy and histological subtype or location of the tumor, had no clinical impact [119] (Table II). In turn, Zhang et al. observed the influence of the tumor differentiation degree on the prognosis in cardiac sarcomas [120]. In the cardiovascular system sarcomas develop considerably less rarely within the large vessels, re-occupying the heart cavities by infiltration. The majority of cardiac sarcomas are located in the right heart; only leiomyosarcoma shows a predilection for the left atrium $[42,49]$. Although there are plenty of reports of left-sided other types of sarcomas, most researchers attribute benign tumors to this site $[42,49]$. Also, other data suggest sarcoma's preference for the left heart $[41,120]$. The sarcoma of the left atrium rarely occupies the area of the fossa ovalis, which is an important difference from myxomas [6]. The majority of them are pleomorphic sarcomas with foci of dedifferentiation into other lines [121]. Other authors suggest that left atrium sarcomas have a more favorable prognosis [122, 123]. Typically, in cardiac sarcoma the following common phenomena are observed: impaired outflow or blood inflow to the heart chambers, valvular dysfunction, arrhythmias, heart failure, low output syndrome, embolic incidents, pericardial effusion, systemic inflammatory response, and non-specific general symptoms, including syncope. In fact, sarcoma location and clinical presentation are unpredictable. This is best illustrated by a case of malignant transformation of cardiac myxoma into MFH described by Kasugai et al. [124]. The increase in inflammatory markers is associated with production of cytokines and release of their free receptors by sarcoma cells [72]. This also alters the blood morphological picture. Furthermore, the blood composition is modified by mechanical hemolysis due to abnormal blood flow caused by the intracardiac tumor mass [77]. Metastases and local recurrences are typically low-differen- tiated sarcomas, with a high mitotic index and large cellular atypia. Histological presentation of the recurrence mostly resembles the original appearance of the tumor tissue, although one may see both the gradual reduction of differentiation of tumor cells and their dedifferentiation. It is also possible for low-differentiated sarcoma to diversify into a more parent-like tissue, from which it originated [49]. For further diagnosis of the patient it is therefore important that the pathologist may have an insight into the previous, microscopic tissue material. In addition, along with tumor progression molecular defects accumulate [35]. The histopathological study protocol proposed by Hammond is a good way to enhance cooperation between the cardiac surgeon, pathomorphologist and oncologist [125]. Any case of cardiac myxoma doubtful as to the status of its malignancy should be supplemented with intraoperative microscopic examination and possible widening of margins of healthy tissue around the resected lesions. The adaptation of endoscopic methods for the removal of benign tumors of the heart with prior histopathological diagnosis by biopsy under CT or ultrasound control brings a number of benefits. However, the use of such treatment in the case of sarcomas may be questionable, due to the radicalness of resection and size of tumors. In addition, it is important to perform direct intraoperative assessment of cardiac structures and verification of the findings derived by the preoperative imaging. On the other hand, according to De Geest et al. [88], such access limits manipulations of the tumor and increases the risk of an embolism. In the case of gastrointestinal sarcomas, laparoscopic methods do not apply as they are related to a very high risk of intraoperative damage to the tumor and "implantation" in the surrounding structures. According to the authors of the article, application of endoscopic methods in selected cases of cardiac sarcoma operations, which aim to reduce the "mass effect of the tumor", seems to be reasonable - primarily because these operations affect the patient's condition less and total resection is usually not possible. In view of the presented data, the term "clinical masks of sarcoma" seems to be appropriate. Correct and prompt diagnosis of malignant tumors of the heart is extremely im-

Table II. Correlation of the extent of the resection with the risk of local recurrence

\begin{tabular}{|lc|}
\hline Excision type & Predicted frequency of local recurrence \\
\hline Operation with an intraneoplastic margin & $100 \%$ \\
\hline Operation within the margins (tumor's enucleation with a pseudosac) & $70-90 \%$ \\
\hline Operation with a wide margin & $\mathrm{G} 1-20-30 \%$ \\
& $\mathrm{G} 2, \mathrm{G} 3-50 \%$ \\
\hline Operation with excision of the muscular compartment & $5 \%$ \\
\hline
\end{tabular}


portant. Unfortunately, there is still a significant rate of false diagnoses and inappropriate therapy being conducted $[12,19,126]$. This clearly indicates the need to broaden diagnostics with transoesophageal echocardiography in each cardiological and cardiosurgical case that remains even slightly ambiguous [14]. Magnetic resonance or computed tomography even allows for targeting of the final diagnosis. The rarity, difficulty in determining the pathomorphological nature and location of the primary lesion, and continuing refinement of diagnostic methods result in a misstatement of the statistical analysis of heart sarcomas. These facts are probably the primary cause of the controversies in the literature. A turning point in the treatment of cardiac sarcomas is still expected. The elementary barrier is the physiological and cytological specificity of cardiomyocytes. Although early diagnosis with immediately carried out radical surgery is one of the conditions to achieve a total cure, it seems that a new strategy in the neoadjuvant or adjuvant therapy is needed. Implementation of targeted therapy carries great hopes. For this, however, extended molecular analysis of each new case of sarcoma of the heart should be conducted. Multidisciplinary centers obtain the best possible results of soft tissue sarcoma treatment [115]. Cooperation at all levels between the cardiac surgeon, cardiologist, and an oncologist in a single clinical center would create incomparably greater possibilities, while reducing the execution time of individual therapeutic procedures.

\section{References}

1. Sparrow PJ, Kurian JB, Jones TR, Sivananthan MU. MR Imaging of cardiac tumors. RadioGraphics 2005; 25: 1255-76.

2. Maraj S, Pressman GS, Figueredo VM. Primary cardiac tumors. Int J Cardiol 2009; 133: 152-6.

3. Haponiuk I, Skalski JH, Wroniecki K. Cardiac tumors. In: Pediatric cardiac surgery. Cardiac surgery of the congenital cardiac defects in detail [Polish]. Skalski JH, Religa Z (eds). „Śląsk” Wydaw. Nauk., Katowice 2003; 424-36.

4. Castillo JG, Semin SG. Characterization and management of cardiac tumors. Cardiothorac Vasc Anesth 2010; 14: 6-20.

5. Riberi A, Gariboldi V, Grisoli D, Collart F. Cardiac tumors. Rev Pneumol Clin 2010; 66: 95-103.

6. Grebenc ML, Rosado de Christenson ML, Burke AP, Green CE, Galvin JR. Primary cardiac and pericardial neoplasms: radiologic-pathologic correlation. AFIP Arch 2000; 20: 1073-103.

7. Malec E, Gajewski M, Skura P. Left ventricular intracardiac tumour diagnosed by echocardiography in a 17-year-old girl - a case report [Polish]. Pol Heart J 2007; 65: 47-9.

8. Virmani R, Burke A, Saunders WB. Atlas of cardiovascular pathology. 1996; 94 (google books).

9. Amonkar GP, Deshpande JR. Cardiac angiosarcoma. Cardiovasc Pathol 2006; 15: 57-8.
10. Ananthasubramaniam K, Farha A. Primary right atrial angiosarcoma mimicking acute pericarditis, pulmonary embolism, and tricuspid stenosis. Heart 1999; 81: 556-8.

11. Meng Q, Lai H, Lima J, Tong W, Qian Y, Lai S. Echocardiography and pathologic characteristics of primary cardiac tumors: a study of 149 cases. Int J Cardiol 2002; 84: 69-75.

12. Fonseca V, Reis G, Lourenço C, et al. Pulmonary metastasis in a cardiac angiosarcoma - case report and discussion. Rev Port Pneumol 2009; 15: 1175-84.

13. Bennett KR, Brandon LH, Bennett FT. Angina pectoris from an unexpected cause. J Miss State Med Assoc 1997; 38: 441-5.

14. Plana JC, Iskander SS, Ostrowski ML, et al. Cardiac angiosarcoma: an unusual presentation simulating mitral stenosis and constrictive-effusive pericarditis. J Am Soc Echocardiogr 2003; 16: 1331-3.

15. Kontogiorgi M, Exarchos D, Charitos C, et al. Primary right atrium angiosarcoma mimicking pericarditis. World J Surg Oncol 2007; 5: 120-3.

16. Holtan SG, Allen RD, Henkel DM, et al. Angiosarcoma of the pericardium presenting as hemorrhagic pleuropericarditis, cardiac tamponade, and thromboembolic phenomena. Int J Cardiol 2007; 115: e8-9.

17. Królczyk J, Fornal M, Janicki K, Wilkołek P, Krochin M, Tracz W. Angiosarcoma (hemangiosarcoma) cordis. Przegl Lek 2003; 60: 123-5.

18. Kim DM, Hong JH, Kim SY, et al. Primary cardiac angiosarcoma presenting with cardiac tamponade. Korean Circ J 2010; 40: 86-9.

19. Mukohara N, Tobe S, Azami T. Angiosarcoma causing cardiac rupture. Jpn J Thorac Cardiovasc Surg 2001; 49: 516-8.

20. Keohane ME, Lazzam C, Halperin JL, Strauchen JA, Ergin MA. Angiosarcoma of the left atrium mimicking myxoma: case report. Hum Pathol 1989; 20: 599-601.

21. Burke A, Jeudy J Jr, Virmani R. Cardiac tumours: an update. Heart 2008; 94: 117-23.

22. Grollier G, Commeau P, Iselin M, et al. Angiosarcoma localized in the right cardiac cavities. Apropos of a case. Ann Cardiol Angeiol (Paris) 1983; 32: 59-62.

23. Walkes JCM, Smythe WR, Reardon MJ, Cohn L (eds.) Cardiac neoplasms cardiac surgery in the adult. McGraw-Hill, New York 2008; 1479-510.

24. Liombart-Cussac A, Pivot X, Contesso G, et al. Adjuvant chemotherapy for primary cardiac sarcomas: the IGR experience. Br J Cancer 1998; 78: 1624-8.

25. Baker KS, Anderson JR, Lobe TE, et al. Children from ethnic minorities have benefited equally as other children from contemporary therapy for rhabdomyosarcoma: a report from the Intergroup Rhabdomyosarcoma Study Group. J Clin Oncol 2002; 20: 4428-33.

26. Shapiro LM. Cardiac tumors: diagnosis and management. Heart 2001; 85: 218-22.

27. Damjanovic M, Djordjevic-Radojkovic D, Perisic Z, et al. Heart failure caused by cardiac rhabdomyosarcoma. Kardiol Pol 2008; 66: 1207-9.

28. Chlumský J, Holá D, Hlaváček K, et al. Cardiac rhabdomyosarcoma. Exp Clin Cardiol 2001; 6: 114-7.

29. Kocańda S, Rdzanek A, Filipiak KJ. Primary cardiac tumors [Polish]. Forum Kardiologow 2000; 5: 65-73.

30. Castorino F, Masiello P, Quattrocchi E, Di Benedett G. Primary cardiac rhabdomyosarcoma of the left atrium. Tex Heart Inst J 2000; 27: 206-8.

31. Ishiguro N, Motoi T, Araki N, Ito H, Moriyama M, Yoshida $\mathrm{H}$. Expression of cardiac ankyrin repeat protein, 
CARP, in malignant tumors: diagnostic use of CARP protein immunostaining in rhabdomyosarcoma. Hum Pathol 2008; 39: 1673-9.

32. Lo Re V 3rd, Fox KR, Ferrari VA, Scott CH, Kossev PM, Kostman JR. Hypereosinophilia associated with cardiac rhabdomyosarcoma. Am J Hematol 2003; 74: 64-7.

33. Sullivan MJ, Wanger GP, Schonfeld SA, Bashore TM. Cardiac rhabdomyosarcoma presenting as hypereosinophilic syndrome. Am J Cardiol 1983; 51: 909-10.

34. Lodha A, Haran M, Shetty V, Sadiq A, Hollander G, Shani J. Hypereosinophilic syndrome presenting with biventricular cardiac thrombi. Echocardiography 2010; 27: E57-9.

35. Wang R, Titley JC, Lu YJ, et al. Loss of 13q14-q21 and gain of $5 p 14$-pter in the progression of leiomyosarcoma. Mod Pathol 2003; 16: 778-85.

36. Malyshev M, Safuanov A, Gladyshev I, Trushyna V, Abramovskaya L, Malyshev A. Primary left atrial leiomyosarcoma: literature review and lessons of a case. Asian Cardiovasc Thorac Ann 2006; 14: 435-40.

37. Vaello A, Millán MV, Fuentes ME, Giménez F. Superior vena cava syndrome as the first manifestation of a primary cardiac leiomyosarcoma. Rev Esp Cardiol 2007; 60: 327-9.

38. Weaver MJ, Abraham JA. Leiomyosarcoma of the bone and soft tissue: a review. Electronic sarcoma update newsletter 2007; 4, 3.

39. Hattori Y, Iriyama T, Watanabe K, Negi K, Takeda I, Sugimura S. Rapidly growing primary cardiac leiomyosarcoma: report of a case. Surg Today 2000; 30: 838-40.

40. Malec E, Gajewski M, Skura P. Guz lewej komory wykryty w badaniu echokardiograficznym u 17-letniej dziewczyny [Polish]. Kardiol Pol 2007; 65: 47-9.

41. Ogimoto A, Hamada M, Ohtsuka T, et al. Rapid progression of primary cardiac leiomyosarcoma with obstruction of the left ventricular outflow tract and mitral stenosis. Intern Med 2003; 42: 827-30.

42. Morin JE, Rahal DP, Huttner I. Myxoid leiomyosarcoma of the left atrium: a rare malignancy of the heart and its comparison with atrial myxoma. Can J Cardiol 2001; 17: 331-6.

43. Schröder S, Walker T, Greschniok A, Herdeg C, Karsch KR, Ziemer G. Primary cardiac leiomyosarcoma originating from the pulmonary valve. Case report and review of the literature. J Cardiovasc Surg (Torino) 2001; 42: 53-6.

44. Gustafson P. Soft tissue sarcoma. Epidemiology and prognosis in 508 patients. Acta Orthop Scand Suppl. 1994; 259: 1-31.

45. Strutyńska-Karpińska M, Markocka-Mączka K, Rabczyński J. Myxomatous fibrosarcoma of the cervix [Polish]. Adv Clin Exp Med 2003; 12: 669-71.

46. Takeuchi I, Kawaguchi T, Kimura Y, et al. Primary cardiac osteosarcoma in a young man with severe congestive heart failure. Intern Med 2007; 46: 649-51.

47. Smith PJ, Almeida B, Krajacevic J, Taylor B. Sclerosing epithelioid fibrosarcoma as a rare cause of ascites in a young man: a case report. J Med Case Rep 2008; 2: 248-50.

48. Lim YT, Lee CN, Chia BL. Images of cardiology: fibrosarcoma of the heart. Heart 1998; 80: 369.

49. Fletcher CD. The histological features of local recurrences of soft tissue sarcomas. Pathologe 1994; 15: 196-200.

50. Titi S, Sycz K, Umiński M. Primary fibrosarcoma of the thyroid gland - a case report. Pol J Pathol 2007; 58: 59-62.
51. Van Veer H, Meuris B, Verbeken E, Herijgers P. Primary atrial fibrosarcoma of the heart. Cardiovasc Pathol 2008; 17: 325-8.

52. Rathinam S, Kuntz H, Panting J, Kalkat MS. Inflammatory myofibroblastic tumour at the pacemaker site. Inter Cardiovasc Thorac Surg 2010; 10: 443-5.

53. Lazaros GA, Matsakas EP, Madas JS, et al. Primary myxofibrosarcoma of the left atrium: case report and review of the literature. Angiology 2008; 59: 632-5.

54. Gomez-Rubin MC, Rios JC, Dobarro D, et al. A recidivant primary cardiac osteosarcoma: the role of bone scans. Cardiovasc Pathol 2010; 19: 55-8.

55. Bussani R, De-Giorgio F, Abbate A, Silvestri F. Cardiac metastases. J Clin Pathol 2007; 60: 27-34.

56. Zhang L, Ellis J, Kumar D, Deng T. Primary right ventricular osteosarcoma. Can J Cardiol 2008; 24: 225-6.

57. Burke AP, Virmani R. Osteosarcomas of the heart. Am J Surg Pathol 1991; 15: 289-95.

58. Nowrangi SK, Ammash NM, Edwards WD, Breen JF, Edmonson JH. Calcified left ventricular mass: unusual clinical, echocardiographic, and computed tomographic findings of primary cardiac osteosarcoma. Mayo Clin Proc 2000; 75: 743-7.

59. Schneiderman H, Fordham EW, Goren CC, McCall AR, Rosenberg MS, Rozek S. Primary cardiac osteosarcoma: multidisciplinary aspects applicable to extraskeletal osteosarcoma generally. CA Cancer J Clin 1984; 34; 110-7.

60. Erlandson RA. Controversial tumors of fibroblastic differentiation [Abstract]. Companion Society Meeting of the Society for Ultrastructural Pathology. Pathology of soft tissue tumors; 1999 March 21; San Francisco. California [Internet].

61. de Saint Aubain N. Pleomorphic cell tumors of soft tissue. Differential diagnosis. Forpath - Jan 2004.

62. Al-Agha OM, Igbokwe AA. Malignant fibrous histiocytoma. Between the past and the present. Arch Pathol Lab Med 2008; 132: 1030-5.

63. Fletcher CD, Gustafson P, Rydholm A, Willén H, Akerman M. Clinicopathologic re-evaluation of 100 malignant fibrous histiocytomas: prognostic relevance of subclassification. J Clin Oncol 2001; 19: 3045-50.

64. Burke A, Jeudy Jr J, Virmani R. Cardiac tumors. In: Textbook of cardiovascular medicine. 3rd ed. Topol EJ, Califf RM. Lippincott Williams \& Wilkins 2007; 710-8.

65. Pająk J, Ograbek-Krol M, Dobrosz Z, Pierzchała W. Primary cardiac malignant fibrous histiocytoma in 47-year-old woman [Polish]. Wiad Lek 2005; 58: 345-9.

66. Ahlén J, Weng WW, Brosjö O, Von Rosen A, Larsson O, Larsson C. Evaluation of immunohistochemical parameters as prognostic markers in malignant fibrous histiocytoma. Oncol Rep 2003; 10: 1641-5.

67. Gibbs JF, Huang PP, Lee RJ, et al. Malignant fibrous histiocytoma: an institutional review. Cancer Invest 2001; 19: 23-7.

68. Choong PF, Mandahl N, Mertens F, et al. 19p+ marker chromosome correlates with relapse in malignant fibrous histiocytoma. Genes Chromosomes Cancer 1996; 16: 88-93.

69. Ohsawa M, Tomita Y, Kuratsu S, Kanno H, Aozasa K. Angiogenesis in malignant fibrous histiocytoma. Oncology 1995; 52: 51-4.

70. Nakanishi H, Araki N, Kudawara I, et al. Clinical implications of serum C-reactive protein levels in malignant fibrous histiocytoma. Int J Cancer 2002; 99: 167-70.

71. Kamińska J, Kowalska M, Kotowicz B, Fuksiewicz M. The prognostic value of cytokine levels in patients 
with cancer [Polish]. Contemp Onkol (Poznan) 2006; 10: 259-62.

72. Recchia F, Saggio G, Amiconi G, et al. Cardiac metastases in malignant fibrous histiocytoma. A case report. Tumori 2006; 92: 76-8.

73. Chuman H. Current topics in the diagnosis and treatment of malignant fibrous histiocytoma. Gan To Kagaku Ryoho 2003; 30: 626-33.

74. Le Doussal V, Coindre JM, Leroux A, et al. Prognostic factors for patients with localized primary malignant fibrous histiocytoma: a multicenter study of $216 \mathrm{pa}-$ tients with multivariate analysis. Cancer 1996; 77: 1823-30.

75. Bacci G, Ferrari S, Picci P, et al. Neoadjuvant chemotherapy in malignant fibrous histiocytoma of the limbs: 10 years of experience (1983-1992) at the Rizzoli Orthopedic Institute. Minerva Med 1996; 87: 135-46.

76. Toda R, Yotsumoto G, Masuda H, Sakata R, Umekita Y. Surgical treatment of malignant fibrous histiocyto$\mathrm{ma}$ in the left atrium and pulmonary veins: report of a case. Surg Today 2002; 32: 270-3.

77. Coller JM, Parente P, Esmore D, New G, Murugasu A, Cooke JC. Large left ventricular metastasis causing left ventricular outflow tract obstruction and haemolysis. Eur J Echocardiogr 2009; 10: 456-8.

78. Catton C. The management of malignant cardiac tumors: clinical considerations. Semin Diagn Pathol 2008; 25: 69-75.

79. Maheshwari AV, Muro-Cacho CA, Cohen JJ, Keisch M, Klos RB, Temple HT. Isolated left-sided metastatic sarcoma of the heart with limb ischemia. A case report. J Bone Joint Surg 2008; 90: 1112-6.

80. Reynen K, Köckeritz U, Strasser RH. Metastases to the heart. Ann Oncol 2004; 15: 375-81.

81. Hallahan DE, Vogelzang NJ, Borow KM, Bostwick DG, Simon MA. Cardiac metastases from soft-tissue sarcomas. J Clin Oncol 1986; 4: 1662-9.

82. Yu K, Liu Y, Wang H, Hu S, Long C. Epidemiological and pathological characteristics of cardiac tumors: a clinical study of 242 cases. Interact Cardiovasc Thorac Surg 2007; 6: 636-9.

83. Kelle S, Paetsch I, Neuss M, et al. Primary fibrosarcoma of the liver infiltrating the right atrium of the heart. Intern J Cardiovasc Imag 2005; 21: 655-8.

84. Exarhos DN, Tavernaraki EA, Kyratzi I, et al. Imaging of cardiac tumors and masses. Hospital Chronicles 2010; 5: 1-9.

85. Nitta R, Sakomura Y, Tanimoto K, et al. Primary cardiac angiosarcoma of the right atrium undiagnosed by transvenous endocardial tumor biopsy. Intern Med 1998; 37: 1023-6.

86. Cusimano RJ. Surgical management of cardiac tumors. Semin Diagn Pathol 2008; 25: 76-81.

87. Hoffmeier A, Deiters S, Schmidt C, et al. Radical resection of cardiac sarcoma. Thorac Cardiovasc Surg 2004; 52: 77-81.

88. De Geest VR, Degrieck I, Van Praet F, et al. Endoscopic cardiac tumor resection. Ann Thorac Surg 2007; 83: 2142-6.

89. Vitovskii RM. Efficacy of the surgical treatment for malignant heart tumors. Klin Khir 2005; 1: 35-8.

90. De Geest VR, Degrieck I, Van Praet F, et al. Endoscopic cardiac tumor resection. Ann Thorac Surg 2007; 83: 2142-6.

91. Kaneko Y, Kobayashi J, Saitoh F, Ono M. Thoracoscopic removal of a papillary fibroelastoma in the left ven- tricular apex. Interact Cardiovasc Thorac Surg 2006; 5 : 640-2.

92. Casselman FP, Gillinov AM, Kasirajan V, Ratliff NB, Cosgrove DM 3rd. Primary synovial sarcoma of the left heart. Ann Thorac Surg 1999; 68: 2329-31.

93. King JJ, Fayssoux RS, Lackman RD, Ogilvie CM. Early outcomes of soft tissue sarcomas presenting with metastases and treated with chemotherapy. Am J Clin Oncol 2009; 32: 308-13.

94. Matsumoto S, Ahmed AR, Kawaguchi N, Manabe J, Matsushita Y. Results of surgery for malignant fibrous histiocytomas of soft tissue. Int J Clin Oncol 2003; 8: 104-9.

95. Putnam Jr JB, Sweeney MS, Colon R, Lanza LA, Frazier $\mathrm{OH}$, Coole DA. Primary cardiac sarcomas. Ann Thorac Surg 1991; 51: 906-10.

96. Shanmugam G. Primary cardiac sarcoma. Eur J Cardiothorac Surg 2006; 29: 925-32.

97. Kodali D, Seetharaman K. Primary cardiac angiosarcoma: case report. Sarcoma 2006; 2006: 39130.

98. Ravi V, Benjamin RS. Systemic therapy for cardiac sarcomas. Methodist Debakey Cardiovasc J 2010; 6: 57-60.

99. Maki RG, D'Adamo DR, Keohan ML, et al. Phase II study of sorafenib in patients with metastatic or recurrent sarcomas. J Clin Oncol 2009; 27: 3133-40.

100. Nakamura-Horigome M, Koyama J, Eizawa T, et al. Successful treatment of primary cardiac angiosarcoma with docetaxel and radiotherapy. Angiology 2008; 59: 368-71.

101. Bakaeen FG, Jaroszewski DE, Rice DC, et al. Outcomes after surgical resection of cardiac sarcoma in the multimodality treatment era. J Thorac Cardiovasc Surg 2009; 137: $1454-60$

102. Sala N, Robert L, Lopez-Pousa A, et al. Neoadjuvant treatment evaluation in soft tissue sarcomas (STS): looking for news in radiologic and pathologic response. J Clin Oncol 2010; 28 (Suppl.): Ae20509.

103. Jassem J, Wełnicka-Jaśkiewicz M. The role of chemotherapy in soft tissue sarcomas [Polish]. Contemp Oncol (Poznan) 1999; 3: 199-202.

104. Oechsle K, Aebert H, Teichmann R, et al. Primary malignant sarcomas of the heart and great vessels - a single center experience. J Clin Oncol 2004; 22 (14 Suppl.): 9044.

105. Mayer F, Aebert H, Rudert M, et al. Primary malignant sarcomas of the heart and great vessels in adult patients: a single-center experience. Oncologist 2007; 12: $1134-42$.

106. Mery GM, Reardon MJ, Haas J, Lazar J, Hindenburg A. A combined modality approach to recurrent cardiac sarcoma resulting in a prolonged remission: a case report. Chest 2003; 123: 1766-8.

107. Okada Y, Akisue T, Hara H, et al. The effect of bevacizumab on tumour growth of malignant fibrous histiocytoma in an animal model. Anticancer Res 2010; 30: 3391-5.

108. Casali PG, Jost L, Sleijfer S, Verweij J; the ESMO Guidelines Working Group. Soft tissue sarcomas: ESMO Clinical Recommendations for diagnosis, treatment and follow-up. Ann Oncol 2008; 19 (Suppl. 2): ii89-93.

109. Chawla SP, Tolcher AW, Staddon AP, et al. Survival results with AP23573, a novel mTOR inhibitor, in patients (pts) with advanced soft tissue or bone sarcomas: update of phase II trial. J Clin Oncol 2007; 25 (18 Suppl.): 10076.

110. Cheng H, Force T. Molecular mechanisms of cardiovascular toxicity of targeted cancer therapeutics. Circ Res 2010; 106: 21-34. 
111. Saad SY, Alkharfy KM, Arafah MM. Cardiotoxic effects of arsenic trioxide/imatinib mesilate combination in rats. J Pharm Pharmacol 2006; 58: 1-7.

112. Rodríguez Cruz E, Cintrom-Maldonado RM, Forber TJ. Treatment of primary cardiac malignancies with orthotopic heart transplantation. Bol Asc Medic 2000; 92: 65-71.

113. Grandmougin D, Fayad G, Decoene C, Pol A, Warembourg H. Total orthotopic heart transplantation for primary cardiac rhabdomyosarcoma: factors influencing long-term survival. Ann Thorac Surg 2001; 71: 1438-41.

114. Engellau J, Anderson H, Rydholm A, et al. Time dependence of prognostic factors for patients with soft tissue sarcoma: a Scandinavian Sarcoma Group Study of 338 malignant fibrous histiocytomas. Scandinavian Sarcoma Group. Cancer 2004; 100: 2233-9.

115. Ruka W, Rutkowski P, Krzakowski M, et al. Soft tissue sarcoma - diagnosis and treatment [Polish]. Onkologia w Praktyce Klinicznej 2009; 5: 198-210.

116. Pigott C, Welker M, Khosla P, Higgins RSD. Improved outcome with multimodality therapy in primary cardiac angiosarcoma. Nature Clin Pract Oncol 2008; 5. 112-5.

117. Simpson L, Kumar SK, Okuno SH, et al. Malignant primary cardiac tumors: review of a single institution experience. Cancer 2008; 112: 2440-6.

118. Peiper M, Zurakowski D, Knoefel WT, Izbicki JR. Malignant fibrous histiocytoma of the extremities and trunk: an institutional review. Surgery 2004; 135: 59-66.

119. Truong PT, Jones SO, Martens B, et al. Treatment and outcomes in adult patients with primary cardiac sarcoma: the British Columbia Cancer Agency experience. Ann Surg Oncol 2009; 16: 3358-65.

120. Zhang PJ, Brooks JS, Goldblum JR, et al. Primary cardiac sarcomas: a clinicopathologic analysis of a series with follow-up information in 17 patients and emphasis on long-term survival. Hum Pathol 2008; 39: 1385-95.

121. Burke A. Primary malignant cardiac tumors. Semin Diagn Pathol 2008; 25: 39-46.

122. Ueda T, Aozasa K, Tsujimoto M, et al. Multivariate analysis for clinical prognostic factors in 163 patients with soft tissue sarcoma. Cancer 1988; 62: 1444-50.

123. Centellaa T, Olivaa E, Andradea IG, Lamasa MJ, Epeldeguia A. A patient with cardiac angiosarcoma who survived for four years. Case report and literature review. Rev Esp Cardiol 2005; 58: 310-2.

124. Kasugai T, Sakurai M, Yutani C, et al. Sequential malignant transformation of cardiac myxoma. Acta Pathol Jpn 1990; 40: 687-92.

125. Hammond EH. Protocol for the examination of specimens from patients with primary cardiac tumors. Arch Pathol Laboratory Med 1999; 123: 20-2.

126. Kurian KC, Weisshaar D, Parekh H, Berry GJ, Reitz B. Primary cardiac angiosarcoma: case report and review of the literature. Cardiovasc Pathol 2006; 15: 110-2.

127. Kośmider A, Jaszewski R, Marcinkiewicz A, et al. 23year experience on diagnosis and surgical treatment of benign and malignant cardiac tumors. Arch Med Sci 2013; 9: 826-30. 